\title{
Improving Environmental Sanitation, Health, and Well-Being A Conceptual Framework for Integral Interventions
}

\section{Journal Article}

Author(s):

Nguyen-Viet, Hung; Zinsstag, Jakob; Schertenleib, Roland; Zurbrugg, Chris; Obrist, Brigit; Montangero, Agnes; Surkinkul, Narong; Kone, Doulaye; Morel, Antoine; Cisse, Gueladio; Koottatep, Thammarat; Bonfoh, Bassirou; Tanner, Marcel

Publication date:

2009-06

Permanent link:

https://doi.org/10.3929/ethz-b-000083164

Rights / license:

In Copyright - Non-Commercial Use Permitted

Originally published in:

EcoHealth 6(2), https://doi.org/10.1007/s10393-009-0249-6 


\title{
Original Contribution
}

\section{Improving Environmental Sanitation, Health, and Well-Being: A Conceptual Framework for Integral Interventions}

\author{
Hung Nguyen-Viet, ${ }^{1,2}$ Jakob Zinsstag, ${ }^{1}$ Roland Schertenleib, ${ }^{2}$ Chris Zurbrügg, ${ }^{2}$ Brigit Obrist ${ }^{1}$ \\ Agnès Montangero, ${ }^{2}$ Narong Surkinkul, ${ }^{3}$ Doulaye Koné, ${ }^{2}$ Antoine Morel, ${ }^{2,3}$ Guéladio Cissé, ${ }^{4}$ \\ Thammarat Koottatep, ${ }^{3}$ Bassirou Bonfoh, ${ }^{4}$ and Marcel Tanner ${ }^{1}$ \\ ${ }^{1}$ Department of Public Health and Epidemiology, Swiss Tropical Institute, Socinstrasse 57, 4002 Basel, Switzerland \\ ${ }^{2}$ Eawag: Swiss Federal Institute of Aquatic Science and Technology, Department for Water and Sanitation in Developing Countries (Sandec), \\ P.O. Box 611, 8600 Duebendorf, Switzerland \\ ${ }^{3}$ School of Environment, Resources and Development, Asian Institute of Technology, P.O. Box 4, Klong Luang, Pathumthani 12120, Thailand \\ ${ }^{4}$ Centre Suisse de Recherche Scientifique, Abidjan, Côte d'Ivoire
}

\begin{abstract}
We introduce a conceptual framework for improving health and environmental sanitation in urban and peri-urban areas using an approach combining health, ecological, and socioeconomic and cultural assessments. The framework takes into account the three main components: i) health status, ii) physical environment, and iii) socioeconomic and cultural environment. Information on each of these three components can be obtained by using standard disciplinary methods and an innovative combination of these methods. In this way, analyses lead to extended characterization of health, ecological, and social risks while allowing the comprehensive identification of critical control points (CCPs) in relation to biomedical, epidemiological, ecological, and socioeconomic and cultural factors. The proposed concept complements the conventional CCP approach by including an actor perspective that considers vulnerability to risk and patterns of resilience. Interventions deriving from the comprehensive analysis consider biomedical, engineering, and social science perspectives, or a combination of them. By this way, the proposed framework jointly addresses health and environmental sanitation improvements, and recovery and reuse of natural resources. Moreover, interventions encompass not only technical solutions but also behavioral, social, and institutional changes which are derived from the identified resilience patterns. The interventions are assessed with regards to their potential to eliminate or reduce specific risk factors and vulnerability, enhance health status, and assure equity. The framework is conceptualized and validated for the context of urban and peri-urban settings in developing countries focusing on waste, such as excreta, wastewater, and solid waste, their influence on food quality, and their related pathogens, nutrients, and chemical pollutants.
\end{abstract}

Key words: integrated approach, health, environmental sanitation, MFA, QMRA, social sciences

\section{INTRODUCTION}

Published online: November 13, 2009

Correspondence to: Hung Nguyen-Viet, e-mail: hung.nguyen@unibas.ch
Improving health status and conserving natural resource for sustainable development are part of the millennium development goals (MDGs) (United Nations, 2006). Health 
status is clearly governed by physical environment, in particular by environmental sanitation (excreta, wastewater, and solid waste management, drainage and water supply). According to a WHO report, 2.6 billion people worldwide still do not have any acceptable means of sanitation, while 1.1 billion people do not have an improved water supply (WHO/UNICEF, 2006). Waterborne diseases remain one of the main causes of disability-adjusted life year (DALY) (Murray and Lopez, 1996). With the extensive use and depletion of natural resources, the question how to minimize resource use is of highest priority. Recovery and reuse of resources from wastes while taking into account health safety and their effectiveness have been raised (Nhapi et al., 2003; Miller, 2006). It is also obvious that social, economic, and cultural factors play a crucial role in achieving health improvements (Marmot, 1998; Anderson et al., 2003). Research on the impact of physical, socioeconomic, and cultural environments on health, and on how to reduce health risks by improving these environments, has been abundantly performed. However, the assessments of the impact as well as the way of improving health and environment have often been conducted in relative isolation or nonintegration. For example, the combination of health and the physical environment were comprehensively assessed without sufficiently considering social, economic, and cultural factors (Morris et al., 2006), or the link between health and society without taking enough into account physical aspects of the environment (Yen and Syme, 1999; Marmot, 2005). Reviewing the literature shows a definite lack of integrated assessments providing approaches to improve health and environment more effectively. This is particularly relevant in all discussions on urban and peri-urban developments, where disadvantaged population groups face typical drawbacks of the rapid and uncontrolled urbanization (poor environmental sanitation, pollution, overexploitation and degradation of natural resource) and are exposed to risk (McMichael, 2000; Moore et al., 2003; Montgomery and Elimelech, 2007).

The method of material flow analysis (MFA) studies the fluxes of resources used and transformed as they flow through a system (e.g., a region). It proved to be a suitable instrument for early recognition of environmental and resource management problems and development of appropriate measures (Baccini and Brunner, 1991; Brunner and Rechberger, 2004). In developing countries, this method has been recently applied to optimize water and nutrient management in an environmental sanitation system, as in the case in Vietnam and China (Belevi, 2002; Huang et al., 2007; Montangero et al., 2007). However, MFA does not provide information on potential health risks and critical control points (CCPs), which should be known for safe use of natural resources and reuse of waste products.

Quantitative microbial risk assessment (QMRA) estimates the risk of infection in an exposed group, and can be extended to estimate the risk of disease. This allows, accordingly, the assessment of CCPs in food chains (production, transformation, and consumption) and sanitation systems (Haas et al., 1999). This methodology has been more and more used in risk assessment of drinking water (Howard et al., 2006; van Lieverloo et al., 2007) and other practices, such as waste management (Westrell et al., 2004; Eisenberg et al., 2008). Recently, QMRA has been used to assess the risk of infection resulting in high risk of diseases for the population in contact with wastewater (Mara et al., 2007; Seidu et al., 2008).

However, in both cases of MFA and QMRA, additional knowledge is required to assess comprehensively public health risks quantitatively, particularly taking the crucial behavioral dimensions into account.

Epidemiological studies are very important to reveal health risk in relation to food chains and environmental sanitation (Beaglehole et al., 2005). Epidemiology, which is based on a quantitative and qualitative risk assessment at population level, includes with cultural epidemiology, how health and risk are perceived by different populations through experiences, meaning, and behavior related to particular risk (Weiss, 2001). However, even the most comprehensive concept of epidemiology does not address the issues of resource flows/cycles.

The social anthropology approaches are people-centered and examine responses to health risk as processes leading to negative outcomes (vulnerability) or positive outcomes (resilience) from social actors' perspectives (Obrist, 2006). A critical issue for vulnerability reduction and resilience building in contexts of livelihood security is access to livelihood assets and to health, environmental, and social services (Obrist et al., 2007).

Hazard analysis and critical control points (HACCP), initially developed for controlling food microbial hazards, are now intensively used in the food safety control (Sun and Ockerman, 2005) and in water treatment safety (Jagals and Jagals, 2004). In the current context of interdisciplinary research, CCPs in food safety control should be extended to other fields of microbial hazards and polluting substances. Thus, CCPs in material flow systems can be seen in broad perspective encompassing environmental, microbiological, social, and economic dimension. This is not only important 
to weigh CCPs from a broad perspective but also to identify interventions revealed through successful resilience patterns. Finally, any intervention should not only be assessed for its technical efficacy but can only be introduced at large scale for beneficiaries once cost-effectiveness and equityeffectiveness are established and have been validated.

Consequently, this article aims at discussing the various approaches so far applied in understanding the interrelations between environmental sanitation, health, and well-being. Based on this brief review, we propose a conceptual framework combining health status, physical, and socioeconomic and cultural environments to improve health, and minimizing environmental impact focusing on urban and peri-urban areas in developing countries.

\section{Towards an Integrated Approach}

The basic structure of the proposed framework is shown in Fig. 1. The methodological approaches to apply the framework to a specific setting are compiled in Table 1 . The framework starts with a rapid analysis of the health status and the status of the physical as well as the social, cultural, and economic environment. Initially starting with an analysis of the routine databases, health status and well-being can be further assessed through specifically designed epidemiological surveys. Similarly, the status of environmental sanitation can be evaluated by surveys, observation and mapping of water supply, excreta, wastewater, solid waste management, and drainage infrastructures and services, while taking into account the technical, economic, institutional, and organizational aspects. Furthermore, interactions between waste management and the food chain, crops, and livestock can also be included. All combined, this information allows describing the current status of environmental sanitation systems, health, and well-being of the local population and the key interrelations. They provide the basis for understanding the key issues for the improvement of health and environment in a given area/setting.

\section{Physical Environment}

The physical environment describes the status of the environmental sanitation system (water supply, management of liquid and solid wastes, drainage of stormwater). Several methods for assessing the physical environment and

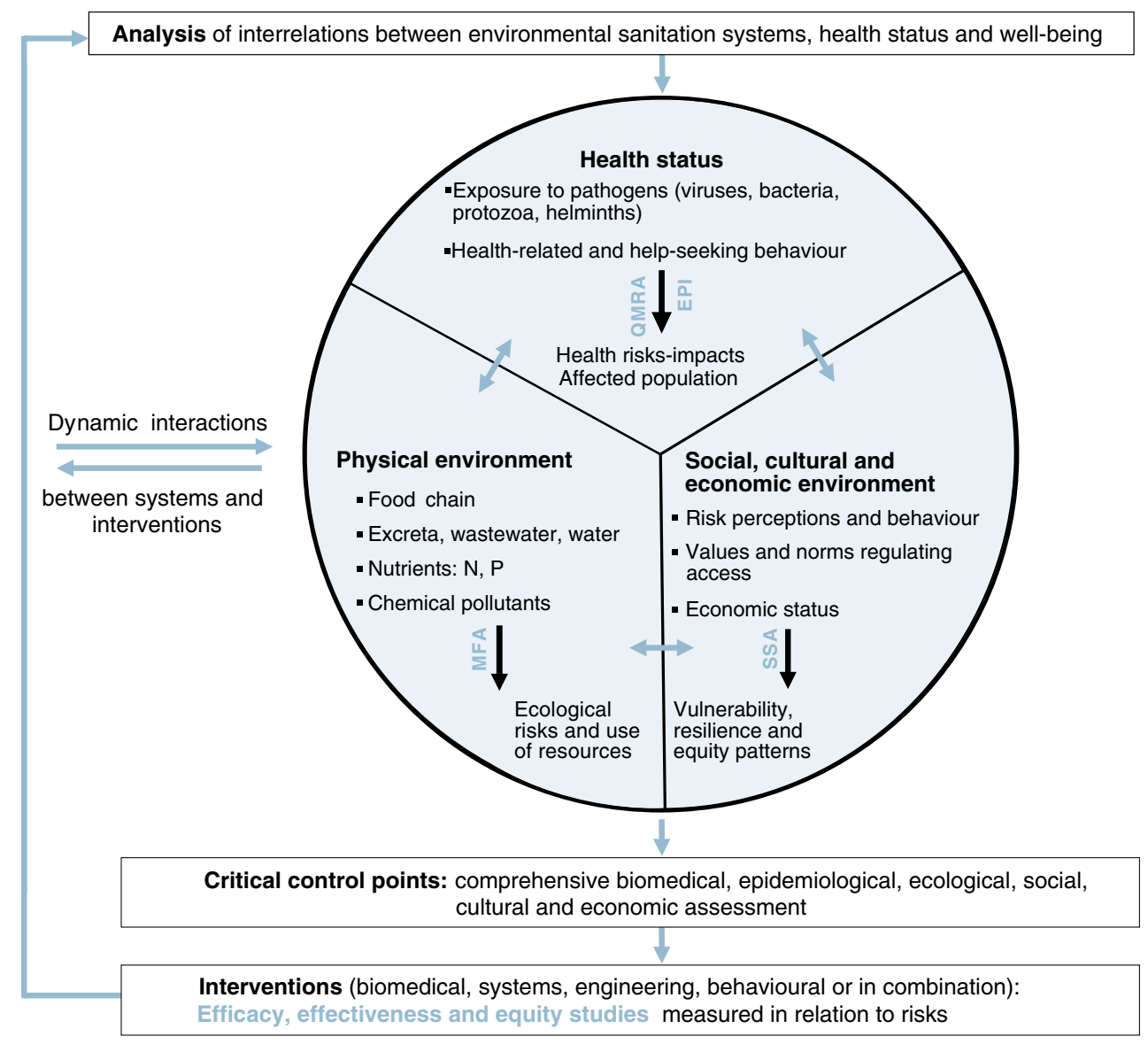

Fig. 1. Conceptual framework of the combination of health and environmental risk assessment for health and environmental sanitation planning. Green characters refer to methodologies used within the conceptual framework (see text for details). QMRA quantitative microbial risk assessment, EPI epidemiology, MFA material flow analysis, SSA social science analysis. 


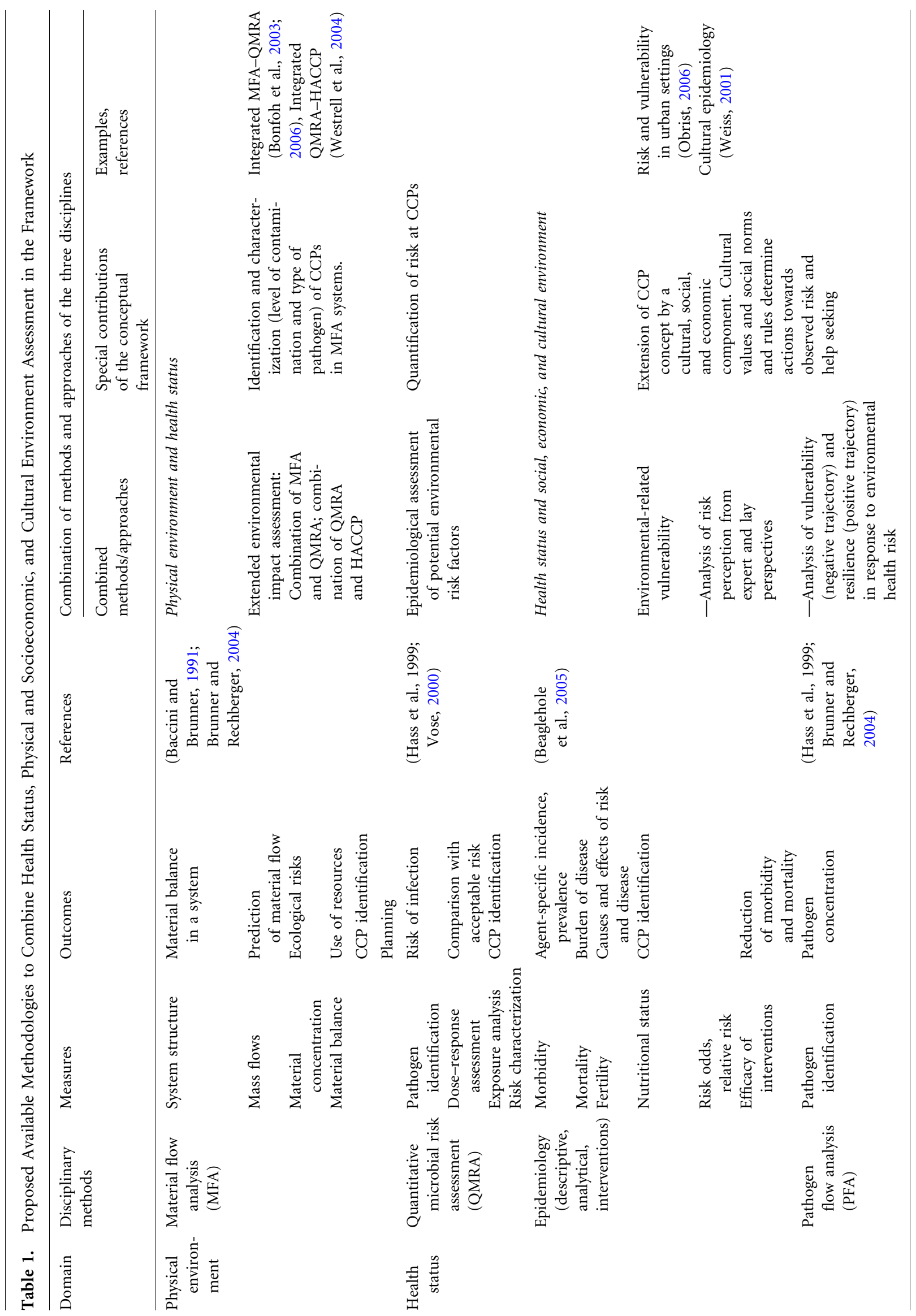




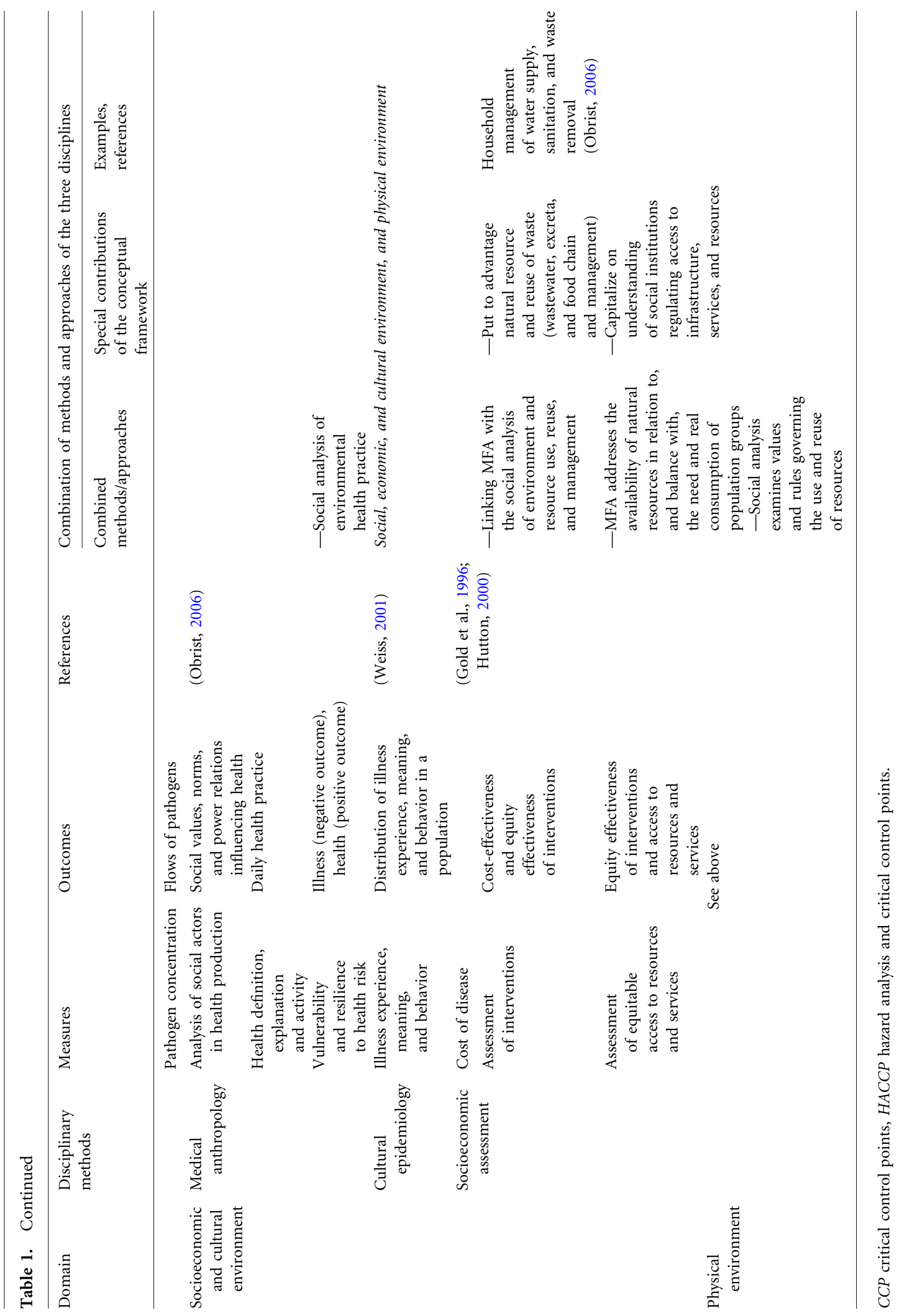


its ecological impacts are available (environmental impact assessment, life cycle assessment, MFA (Baccini and Brunner, 1991; Brunner and Rechberger, 2004), etc.

As the MFA is straightforward to apply, and proven to be effective in developing countries' context with limited data availability (Montangero, 2007; Montangero et al., 2007), we propose to use the MFA for this purpose. The main steps of an MFA are the conceptual representation of processes, their interaction with flows of goods (system analysis), as well as the quantification of mass flow of goods and substances. The tool of MFA provides useful information for the identification of key factors determining material flows ("CCPs") and the planning of interventions aiming at reducing resource consumption and pollutant loads to the environment. In our context, the focus rests on the most relevant "goods" that play an important role with regard to human health and ecological impact and the "substances" these goods contain. Main "goods" are water, food, excreta, and wastewater, and the main "substances" taken into account are pathogens, nutrients, and chemical pollutants.

\section{Social, Economic, and Cultural Environment}

This component entails the approaches of medical anthropology, cultural epidemiology, and social economics, grouped as social science analyses (SSA). A main focus of the approach lies in considering the vulnerability and resilience of the populations (Obrist, 2006), and their risk perceptions through experiences, meaning, and behavior related to particular illness entities (Kleinman, 1981; Weiss, 2001). Furthermore, economic appraisal methodology is used to assess the costs and cost-effectiveness of the interventions. Combining economic appraisal with epidemiological and social and cultural data allows analysis on how there is an equitable access to resources and services, and to what degree equity effectiveness could be achieved (Gold et al., 1996; Hutton, 2000).

\section{Health Status}

Many methodologies are used to assess and improve health status. For our framework, classical (Beaglehole et al., 2005) and cultural epidemiology (Weiss, 2001) and QMRA are proposed as the key methodologies to assess health and identify the determinants of disease burdens. While the basic approaches of epidemiology are well known, validated, and applied (Beaglehole et al., 2005), QMRA has been recently applied in health status assessments, and been recommended in risk assessments for the safe use of wastewater, excreta, and graywater, and for drinking-water quality (WHO, 2006a, b). The addition of QMRA to epidemiology (EPI) is motivated by the quantitative aspect of this method, which is based on the combination of available information on exposure and dose-response to calculate the estimated risk of having infection and disease burden related to pathogens exposure (Haas et al., 1999; Vose, 2000). Indeed, QMRA has been used in various risk assessments and shown to be effectively applied in developing countries, even with limited data (Howard et al., 2006; Benke and Hamilton, 2008). The identification of pathogens (viruses, bacteria, protozoa, and helminths) constitutes a main step and will effectively complement epidemiology (Fig. 1). Clearly, the QMRA quantifies the risks of infection, while epidemiology aims at identifying the determinants and distribution of diseases, burden of disease, effects on demographic parameters, causes, and effects of risk and diseases. QMRA and epidemiology consequently allow the identification of CCPs where measure needs to be enacted in order to improve health by reducing the morbidity and mortality.

In analogy to MFA, we suggest the method of pathogen flow analysis (PFA) (Table 1). The PFA focuses on most relevant pathways of pathogen transmission in the systems to quantify pathogen concentrations, pathogen flows, and their respective reduction or increase in different points of the environmental sanitation systems. The PFA approach will allow identifying the CCPs regarding pathogens to be tackled.

\section{Comprehensive Critical Control Points}

CCPs are conventionally defined, in food safety, as any step at which control can be applied, and is essential to prevent or eliminate a food safety hazard or reduce it to an acceptable level (National Advisory Committee on Microbiological Criteria for Foods, 1997). CCPs in our framework result from the analyses of the three components described above. Therefore, integrated CCPs are taken into account and identified from different perspectives, such as by comprehensive biomedical, epidemiological (health), social, cultural, and economic assessment (social sciences), and ecological assessment (physical environment) (Fig. 1). CCPs, as used in our framework, retain the traditional CCP definition related to food chains, but are further complemented by other risks relating to pathogens in drinking water, wastewater, excreta, and solid wastes, as well as 
inclusion of the social and cultural perspectives that consider the concept of vulnerability and resilience.

\section{Interventions}

Once the CCPs are identified, interventions can be comparatively assessed in view of the best contributing to improving health and minimizing impact on the environment and the use of resources in a given area. Interventions established based on this background will be integrated as they will take into account the professionally defined needs and the demand of the populations concerned. Consequently, this will allow priority setting, based on reconciled needs and demands.

Figure 1 further shows the dynamics between the components of the framework and the interventions. The iterative process ensures that interventions are tailored to the needs and demands of any given setting, and allows respective readjustments and strengthening of any intervention or component of intervention.

Assessment of impact, also shown in Fig. 1, allows a critical analysis of the impact on equity effectiveness, and to understand (i) to what extent, (ii) at which level, and (iii) by which determinants equity effectiveness is achieved. Moreover, such impact assessment can represent internal and external validation of the CCPs.

\section{New Concept and Its Underlying EXAMPLES}

The framework as presented in Fig. 1 and elaborated above derives from past experiences in different geographical and disciplinary settings. The building blocks of on-site-experience of the framework are briefly discussed in the following section.

\section{Physical Environment and Health Status}

Combining MFA and QMRA to take into account sustainable resource management, while minimizing ecological impact and human health risk is an essential element of the framework. To our knowledge, this kind of approach has not been applied before. Some studies have tackled this topic using similar approaches, however, not with a specific methodological link or reference to MFA or QMRA. For example, a study in Bamako (Mali) focused on dynamics of raw milk quality in the distribution and consumption chain. The microbiological quality of raw cows' milk was assessed at different intervals along the milk production and transportation chain, starting from the udder up to the sales points (Bonfoh et al., 2003). This study shows that containers for milk storage and transportation conditions (time and temperature) play a major role in the contamination and recontamination of milk by Enterobacteriaceae and Staphylococcus aureus (Bonfoh et al., 2003). This example illustrates that understanding the milk chain (MFA system) and the dynamics of contamination is crucial to identify and characterize the CCPs.

Another advantage of combining physical and health assessment consists in quantifying the risk at CCPs. Although not directly related to sanitation, the example of Hetzel et al. (2004) shows the risk of having diarrhea and vomiting related to milk consumption in Mali and showed that consuming milk represents a significant risk. Moreover, this risk was not correctly perceived by most consumers. For instance, people were unaware of the potential risks of milk consumption, thus the low awareness may increase the risk of milk consumption.

The combination of QMRA and HACCP also reveals advantages in risk management. For example, Westrell et al. (2004) used a combination of QMRA and HACCP for management of pathogens in wastewater and sewage sludge treatment and reuse. In this study, HACCP was applied for identifying and controlling exposure to pathogens during normal sludge and wastewater handling, whereas QMRA was performed to prioritize pathogen hazards for control purposes. The highest individual health risk from a single exposure and the worst-case situation were thus identified.

Once CCPs are identified and risk assessed, appropriate interventions are needed to prevent and reduce risk caused by the contamination. Following up with the example of the previous paragraph, Bonfoh et al. (2006) proposed and tested an intervention to improve milk quality. The intervention consisted of washing and disinfecting containers for fresh milk sold in Bamako. The results obtained were very encouraging, showing that the total counts and Enterobacteriaceae counts were significantly reduced at the selling point (Bonfoh et al., 2006).

\section{Socioeconomic and Cultural Environment and Health Status}

Public health studies have traditionally assessed risk quantitatively, resulting in absolute, relative, and attributable risks as defined by experts. Based on the risk quanti- 
fication, decisions on interventions were made. However, the interventions are not really effective if the affected population does not accept them. In this case, it is necessary to consider the illness meanings, behaviors, and experiences of people as, for instance, a multi-country study on tuberculosis in India, Bangladesh, Malawi, and Colombia showed (WHO/TDR, 2006). Always from the case study of Bonfoh et al. (2006), the compliance of population to a given intervention is determined by its cost and the perceived financial outcome. Moreover, responses to health risks leading to negative outcomes (vulnerability) are not only due to risk exposure but also to a lack of means (Chambers, 1989). Vulnerability analysis allows for a more comprehensive understanding of health in contexts of livelihood insecurity, as exemplified in a study on women in urban settings in Dar es Salaam, Tanzania (Obrist, 2006). These contributions have extended the concept of CCPs by cultural and social perspectives. Interventions thus become more adequate to, and acceptable for, populations concerned and, thus, increase equity effectiveness.

\section{Physical Environment Linked to Socioeconomic and Cultural Environment}

The framework relies on integrating MFA into the analyses of behavior towards resource use, reuse, and management. MFA addresses the consumption, availability of natural resources, and impact of their use, whereas a social analysis examines values and rules governing the use and reuse of resource. Availability of resources, such as water, has been compared to actual extraction of these resources using MFA (Schandl and Eisenmenger, 2006; Montangero et al., 2007). Kytzia et al. (2004) attempted to consider the resource consumption (e.g., energy) in food production using economically extended-MFA. More recently, MFA was applied as an alternative approach to assess and address water quality degradation in rivers of developing and fast industrializing countries with the focus on nutrient pollution loads (nitrogen and phosphorus) to the river (Schaffner, 2007). Binder (2007) attempted to couple social sciences modeling approaches to MFA, and showed that the large share of these approaches stem from economics, as these models have similar data and modeling structures as the material flow models, and concluded that the coupling approaches can support a better system understanding and allow for estimating the potential effects of economic policies on material flows.
When considering the interrelations between health, well-being, and social environment, the addition of MFA and the understanding of peoples' behavior towards environment and social institutions regulating access to infrastructure, services, and resources become essential. Combining social, economic, and physical environments allows not only characterizing and identifying the status of natural resource or materials of interest, but also understanding power structures in using resources. The combined approach enhances awareness on natural resource use and environmental protection, and consequently leads to optimized use of natural resources. This is particularly interesting in developing countries where, in contrast to developed countries, centralized waste treatment is hardly, or is not, affordable for a large proportion of the population (Parkinson and Tayler, 2003; Schertenleib, 2005).

\section{INSIGHTS FROM CASE StUdies}

We are testing this framework in three case studies in South-east Asia (Vietnam and Thailand) and in West Africa (Côte d'Ivoire). In Hanam, a Northern Province of Vietnam has been chosen as a peri-urban study site. $\mathrm{Hu}$ man excreta and wastewater reuse in agriculture and aquaculture has been identified as an issue of environmental sanitation and agriculture, and health and wellbeing.

\section{Physical Environment}

MFA has been used for analyzing environmental sanitation and agriculture systems with the emphasis on nutrient flow of nitrogen $(\mathrm{N})$ and phosphorus $(\mathrm{P})$. Primary results show that onsite sanitation and crop production discharge the largest flows of $\mathrm{N}$ and $\mathrm{P}$ into water bodies through drainage systems (CCPs), thus options are expected to mitigate environmental impact while making values from wastes, for instance, as fertilizers.

\section{Health Status}

A set of epidemiological and QMRA studies have been carried out to look at the health effect of wastewater and excreta reuse. Thus, a cross-sectional study on diarrhea, helminth and protozoan infection prevalence related to excreta and wastewater reuse, and a case-control study of Entamoeba histolytica infection to identify exposures to 
wastewater and excreta responsible for this infection have been conducted. A 1-year follow-up study will be launched to further explore the link between diarrhea and excreta and wastewater reuse. In parallel, QMRA is being used to assess diarrhea infection risk of wastewater and excreta reuse with a focus on protozoa and bacteria, and a followup of risk surveillance during 1 year at different exposure points (CCPs).

\section{Social, Economic, and Cultural Environment}

A study is looking at the perception on health risk and ability of people to prevent risk caused by wastewater and excreta reuse. The first survey focusing on threat appraisal found that people recognize black color and bad smell of wastewater, bad smell of excreta, and inappropriate practice of excreta management, and suspected diseases by contact with excreta wastewater as threats.

The cases of Thailand and Ivory Coast have also identified wastewater discharged into the canals as an issue for health and environment in the urban and peri-urban setting of Pathumthani and Abidjan, respectively. In Pathumthani, we assessed health risks related to wastewater reuse with QMRA, which identified the critical risk behaviors, leading to estimates of the burden of disease due to exposure to wastewater. The main routes of domestic waste flows and transmission of pathogens in peri-urban agriculture and different scenarios were identified. QMRA focused on different groups of people highly exposed to wastewater, like farmers working in the field, and showed that proposed scenarios could significantly reduce health risk and improve the environment (Surinkul and Koottatep, 2009). Similarly to the case in Vietnam, a social study assessing the perception on health risk of contact with wastewater showed that although the environmental situation in this area is deplorable, the water and sanitation services and facilities are adequate, and people, as well as the community and authorities, give facilities and hygiene behavior a high priority.

In Abidjan, a study on infection risk focusing on exposure to wastewater from canals using QMRA has shown that yearly infection risks from involuntary ingestion of canal water in different points and scenarios, in particular collecting and cleaning solid wastes (e.g., plastic bag) in the canal, were largely higher than acceptable risks as defined by WHO. MFA study has looked at wastewater management in the same area and identified onsite sanitation (septic tank and latrines) and drainage as the main contribution of $\mathrm{N}$ and $\mathrm{P}$ discharge to soils and the lagoon (CCPs). Three scenarios with perspectives of treating and reusing waste were proposed, which has the potential to dramatically reduce the pollution load to the environment. The combination of the three components still needs the data collection to be done.

From these first insights of the three case studies, we could identify the distinctions between the theoretical organization of the framework and the fluid interactions that occurred in the real-life case studies. The key point is to well prepare all components of the framework so that they start at the same time in the best case, or they start as close as possible to each other. In this way, information obtained from different components is complementary and allows a good combination in identifying CCPs. This particularly makes sense for the combination between epidemiological studies, QMRA and MFA.

In practice, diverse information from the three components can be combined as follows: The result of MFA identifies the CCPs in terms of environment and provides a basis for health status research. The actual risks identified by epidemiology support and complement the QMRA which assesses the risk of infection, and is fed by the data from PFA, giving CCPs in terms of health risk. Socioeconomic and cultural assessment looks at the behavior and perception of people with regards to these CCPs, but also at the cost and cost-effectiveness. All these assessments allow the identification of appropriate, equitable, and effective interventions.

\section{Synthesis, Outlook, and Research AGENDA}

Most global health initiatives and the efforts to effectively contribute to the achievements of MDGs recognize that a combination of different research methods deriving from various disciplines is necessary to build an integrated framework for a sustainable improvement of health and environment. Our proposed conceptual framework based on numerous on-site-experiences, combines health aspects with physical, socioeconomic, and cultural environments for a given setting. The framework allows, through an iterative process, identifying CCPs and establishing and implementing potential key interventions. Application of the framework based on cyclic and iterative processes ensures that interventions are scrutinized for their efficacy, cost- and equity- effectiveness in a given cultural and social 
context. The agent-host-environment concept in epidemiology (Beaglehole et al., 2005) and the ecohealth concept (Forget and Lebel, 2001; Patz, 2006) each consider the relationships between health and environment. Our conceptual framework is in accordance, but its original contributions lie in the combination of different sectorshealth, environmental sanitation, and society—and in the integrated nature of this combination, which leads to a new approach to addressing problems at the level of research, and public and environmental health action. Specifically, the innovation resides in: (i) the identification and characterization of CCPs in MFA systems; (ii) the quantification of environmental and health risk at CCPs, and the extension of the CCP concept by a social and cultural component which allows identification of help-related and help-seeking behaviors; and finally, (iii) the promotion of minimal resource use, as well as safe reuse of natural resources such as wastewater, excreta, and other wastes.

Based on the design and requirements for each component of the framework, as well as the combination of framework components, the following questions arise and require current and future research:

(i) How can the combination of MFA and QMRA be modeled and used as a planning tool in public health and in environmental sanitation? This primarily requires knowledge of dose-response and exposure to pathogens, and understanding of pathogen behaviors in a MFA system, and variability of specific parameters influencing pathogens.

(ii) How to address the concept of vulnerability and resilience in a public health context in order to understand and predict health- and help-seeking behaviors of people, including their own perceived and/or lived solutions of feasible interventions?

(iii) What are the risks related to reuse of excreta and wastewater in agriculture using QMRA and EPI? What are the acceptable risks, and what are the perceptions of people towards resource consumption and reuse of waste products, particularly, their compromise between resource consumption and its reuse, as well as their awareness of using resources in a sustainable way?

(iv) What are the cost-benefits of existing and improved sanitation facilities and services (investment and recurrent costs, livelihood benefit, nutrition, and reduction of disease burden), and which are the most cost- and equity-effective interventions in different settings? (v) How best to validate the extended concept of CCPs when applying it in QMRA, EPI, MFA, and SSA?

In conclusion, the proposed integrated framework is offered for further discussion and further validation. The authors hope it can be operationalized to contribute effectively to the improvement of health and well-being in many different settings in developing countries.

\section{ACKNOWLEDGMENTS}

We gratefully acknowledge the contributions by $\mathrm{Mr}$. Christoph Lüthi, Dr. Peter Odermatt, Prof. Mitchell Weiss, and Dr. Voranuch Wangsuphachart during the discussions of this framework. This work has been supported by the Swiss National Science Foundation (SNSF) and the Swiss Agency for Development and Cooperation (SCD), through the program of the National Center for Competences in Research (NCCR) North-South.

\section{REFERENCES}

Anderson LM, Scrimshaw SC, Fullilove MT, Fielding JE (2003) The Community Guide's model for linking the social environment to health. American Journal of Preventive Medicine 24: 12-20

Baccini P, Brunner PH (1991) Metabolism of the Anthroposphere, New York: Springer

Beaglehole R, Bonita R, Kjellström T (2005) Basic Epidemiology, Geneva: World Health Organisation

Belevi H (2002) Material flow analysis as a strategic planning tool for regional waste water and solid waste management. In: Proceedings of the GTZ/BMZ \& ATV-DVWK Workshop "Globale Zukunft:Kreislaufwirtschaftskonzepte im kommunalen Abwasserund Fäkalienmanagement," Munich, May 13-15, 2002

Benke KK, Hamilton AJ (2008) Quantitative microbial risk assessment: uncertainty and measures of central tendency for skewed distributions. Stochastic Environmental Research and Risk Assessment 22:533-539

Binder CR (2007) From material flow analysis to material flow management Part I: social sciences modeling approaches coupled to MFA. Journal of Cleaner Production 15:1596-1604

Bonfoh B, Roth C, Traore AN, Fane A, Simbe CF, Alfaroukh IO, et al. (2006) Effect of washing and disinfecting containers on the microbiological quality of fresh milk sold in Bamako (Mali). Food Control 17:153-161

Bonfoh B, Wasem A, Traore AN, Fane A, Spillmann H, Simbe CF, et al. (2003) Microbiological quality of cows' milk taken at different intervals from the udder to the selling point in Bamako (Mali). Food Control 14:495-500

Brunner PH, Rechberger H (2004) Pratical Handbook of Material Flow Analysis, Boca Raton, FL: Lewis Publishers

Chambers R (1989) Editorial Introduction: Vulnerability, coping and policy. IDS Bulletin 20. 
Eisenberg JNS, Moore K, Soller JA, Eisenberg D, Colford JM (2008) Microbial risk assessment framework for exposure to amended sludge projects. Environmental Health Perspectives 116:727-733

Forget G, Lebel J (2001) An ecosystem approach to human health. International Journal of Occupational and Environmental Health 7 (Suppl):1-38

Gold MR, Siegel JE, Russell LB, Weinstein MC (1996) Costeffectiveness in Health and Medicine, New York: Oxford University Press

Haas CN, Rose JB, Gerba CP (1999) Quantitative Microbial Risk Assessment, New York: John Wiley \& Sons

Hetzel M, Bonfoh B, Farah Z, Traore M, Simbe CF, Alfaroukh IO, et al. (2004) Diarrhoea, vomiting and the role of milk consumption: perceived and identified risk in Bamako (Mali). Tropical Medicine and International Health 9:1132-1138

Howard G, Pedley S, Tibatemwa S (2006) Quantitative microbial risk assessment to estimate health risks attributable to water supply: can the technique be applied in developing countries with limited data? Journal of Water and Health 4:49-65

Huang DB, Bader HP, Scheidegger R, Schertenleib R, Gujer W (2007) Confronting limitations: new solutions required for urban water management in Kunming City. Journal of Environmental Management 84:49-61

Hutton G (2000) Considerations in Evaluating the Cost-effectiveness of Environmental Health Interventions: Protection of the Human Environment, Geneva: World Health Organization

Jagals C, Jagals P (2004) Application of HACCP principles as a management tool for monitoring and controlling microbiological hazards in water treatment facilities. Water Science and Technology 50:69-76

Kleinman A (1981) Patients and Healers in the Context of Culture, an Exploration of the Borderland between Anthropology, Medicine and Psychiatry, Berkeley, CA: University of California Press

Kytzia S, Faist M, Baccini P (2004) Economically extended-MFA: a material flow approach for a better understanding of food production chain. Journal of Cleaner Production 12:877-889

Mara DD, Sleigh PA, Blumenthal UJ, Carr RM (2007) Health risks in wastewater irrigation: comparing estimates from quantitative microbial risk analyses and epidemiological studies. Journal of Water and Health 5:39-50

Marmot M (2005) The social environment and health. Clinical Medicine 5:244-248

Marmot MG (1998) Improvement of social environment to improve health. The Lancet 351:57-60

McMichael AJ (2000) The urban environment and health in a world of increasing globalization: issues for developing countries. Bulletin of the World Health Organization 78:1117-1126

Miller GW (2006) Integrated concepts in water reuse: managing global water needs. Desalination 187:65-75

Montangero A (2007) Material Flow Analysis for Environmental Sanitation Planning in Developing Countries-An Approach to Assess Material Flows with Limited Data Availability. PhD thesis, Innsbruck, Austria: Leopold-Franzens-University.

Montangero A, Cau LN, Anh NV, Tuan VD, Nga PT, Belevi H (2007) Optimising water and phosphorus management in the urban environmental sanitation system of Hanoi, Vietnam. Science of the Total Environment 384:55-66

Montgomery MA, Elimelech M (2007) Water and sanitation in developing countries: including health in the equation. Environmental Science and Technology 41:17-24
Moore M, Gould P, Keary BS (2003) Global urbanization and impact on health. International Journal of Hygiene and Environmental Health 206:269-278

Morris GP, Beck SA, Hanlon P, Robertson R (2006) Getting strategic about the environment and health. Public Health 120:889-903

Murray C, Lopez A (1996) The Global Burden of Disease: A Comprehensive Assessment of Mortality and Disability from Diseases, Injuries and Risk Factors in 1990 and Projected to 2020, Cambridge, MA: Harvard University Press

National Advisory Committee on Microbiological Criteria for Foods (1997) HACCP Guidelines, Washington, DC: U.S, U.S. Department of Agriculture, National Advisory Committee on Microbiological Criteria for Foods: Food and Drug Administration

Nhapi I, Gijzen HJ, Siebel MA (2003) A conceptual framework for the sustainable management of wastewater in Harare, Zimbabwe. Water Science and Technology 47:11-18

Obrist B (2006) Struggling for Health in the City: An Anthropological Inquiry of Health Vulnerability and Resilience in Dar Es Salaam, Tanzania, Bern, Switzerland: Peter Lang

Obrist B, Iteba N, Lengeler C, Makemba A, Mshana C, Nathan R, et al. (2007) Access to health care in contexts of livelihood insecurity: a framework for analysis and action. PLoS Med 4:e308

Parkinson J, Tayler K (2003) Decentralized wastewater management in peri-urban areas in low-income countries. Environment and Urbanization 15:75-89

Patz JA (2006) EcoHealth ONE: Forging collaboration between ecology and health. EcoHealth 3:66-67

Schaffner M (2007) Applying a Material Flow Analysis Model to Assess River Water Pollution and Mitigation Potentials. A Case Study in the Thachin River Basin, Central Thailand. PhD thesis, Bern, Switzerland: University of Bern.

Schandl H, Eisenmenger N (2006) Regional patterns in global resource extraction. Journal of Industrial Ecology 10:133-147

Schertenleib R (2005) From conventional to advanced environmental sanitation. Water Science and Technology 51:7-14

Seidu R, Heistad A, Amoah P, Drechsel P, Jenssen PD, Stenstrom TA (2008) Quantification of the health risk associated with wastewater reuse in Accra, Ghana: a contribution toward local guidelines. Journal of Water and Health 6:461-471

Sun Y-M, Ockerman HW (2005) A review of the needs and current applications of hazard analysis and critical control point (HACCP) system in foodservice areas. Food Control 16:325-332

Surinkul N, Koottatep T (2009) Advanced sanitation planning tool with health risk assessment: case study in a peri-urban community in Thailand. Human and Ecological Risk Assessment 15:1-14

United Nations (2006) The Eight Millennium Development Goals (MDGs). Available: http://www.un.org/millenniumgoals/index. html [accessed December 18, 2006]

van Lieverloo JHM, Blokker EJM, Medema G (2007) Quantitative microbial risk assessment of distributed drinking water using faecal indicator incidence and concentrations. Journal of Water and Health 5:131-149

Vose D (2000) Risk Analysis: A Quantitative Guide, 2nd ed., Chichester, UK: John Wiley \& Sons

Weiss MG (2001) Cultural epidemiology: an introduction and overview. Anthropology and Medicine 8:1-29

Westrell T, Schonning C, Stenstrom TA, Ashbolt NJ (2004) QMRA (quantitative microbial risk assessment) and HACCP 
(hazard analysis and critical control points) for management of pathogens in wastewater and sewage sludge treatment and reuse. Water Science and Technology 50:23-30

WHO (2006) WHO Guidelines for Drinking-water Quality, 3rd ed., Incorporating First Addendum, Vol. 1: Recommendations, Geneva: World Health Organization

WHO (2006) WHO Guidelines for the Safe Use of Wastewater, Excreta and Greywater, Vol. 2: Wastewater Use in Agriculture, Geneva: World Health Organization

WHO/TDR (2006) Gender and tuberculosis: cross-site analysis and implications of a multi-country study in Bangladesh, India,
Malawi, and Colombia. Social, Economic and Behavioural Research. Report Series No. 3, Geneva: WHO/TDR, pp 1-97.

WHO/UNICEF (2006) Meeting the MDG Drinking Water and Sanitation Target: The Urban and Rural Challenge of the Decade, Geneva: WHO/UNICEF Joint Monitoring Programme for Water Supply and Sanitation

Yen IH, Syme SL (1999) The social environment and health: a discussion of the epidemiologic literature. Annual Review of Public Health 20:287-308 